\title{
Slumber in a cell: Honeycomb used by honey bees for food, brood, heating... and sleeping
}

\author{
Barrett A. Klein ${ }^{\text {Corresp., } 1}$, M. Kathryn Busby ${ }^{2}$ \\ 1 Biology Department, University of Wisconsin-La Crosse, La Crosse, Wisconsin, United States \\ ${ }^{2}$ Graduate Interdisciplinary Program in Entomology and Insect Science, University of Arizona, Tucson, Arizona, United States \\ Corresponding Author: Barrett A. Klein \\ Email address: barrett@pupating.org
}

Sleep appears to play an important role in the lives of honey bees, but to understand how and why, it is essential to accurately identify sleep, and to know when and where it occurs. Viewing normally obscured honey bees in their nests would be necessary to calculate the total quantity and quality of sleep and sleep's relevance to the health and dynamics of a honey bee and its colony. Western honey bees (Apis mellifera) spend much of their time inside cells, and are visible only by the tips of their abdomens when viewed through the walls of an observation hive, or on frames pulled from a typical beehive. Prior studies have suggested that honey bees spend some of their time inside cells resting or sleeping, with ventilatory movements of the abdomen serving as a telltale sign distinguishing sleep from other behaviors. Bouts of abdominal pulses broken by extended pauses (discontinuous ventilation) in an otherwise relatively immobile bee appears to indicate sleep. Can viewing the tips of abdomens consistently and predictably indicate what is happening with the rest of a bee's body when inserted deep inside a honeycomb cell? To distinguish a sleeping bee from a bee maintaining cells, eating, or heating developing brood, we used a miniature observation hive with slices of honeycomb turned in cross-section, and filmed the exposed cells with an infrared-sensitive video camera and a thermal camera. Thermal imaging helped us identify heating bees, but simply observing ventilatory movements, as well as larger motions of the posterior tip of a bee's abdomen was sufficient to noninvasively and predictably distinguish heating and sleeping inside comb cells. Neither behavior is associated with large motions of the abdomen, but heating demands continuous (vs. discontinuous) ventilatory pulsing. Among the four behaviors observed inside cells, sleeping constituted $16.9 \%$ of observations. Accuracy of identifying sleep when restricted to viewing only the tip of an abdomen was $86.6 \%$, and heating was $73.0 \%$. Monitoring abdominal movements of honey bees offers anyone with a view of honeycomb the ability to more fully monitor when and where behaviors of interest are exhibited in a bustling nest. 
1

2

3

4

\section{Slumber in a cell: Honeycomb used by honey bees for food,}

\section{6 brood, heating... and sleeping}

Barrett Anthony Klein ${ }^{1}$, M. Kathryn Busby ${ }^{2}$

16

$17{ }^{1}$ Biology Department, University of Wisconsin - La Crosse, La Crosse, WI, USA

$18{ }^{2}$ Graduate Interdisciplinary Program in Entomology and Insect Science, The University of

19 Arizona, Tucson, AZ, USA

21 Corresponding Author:

22 Barrett Klein ${ }^{1}$

231725 State Street, La Crosse, WI, 54601, USA

24 Email address: barrett@pupating.org 


\section{Abstract}

26 Sleep appears to play an important role in the lives of honey bees, but to understand how and 27 why, it is essential to accurately identify sleep, and to know when and where it occurs. Viewing 28 normally obscured honey bees in their nests would be necessary to calculate the total quantity and quality of sleep and sleep's relevance to the health and dynamics of a honey bee and its colony. Western honey bees (Apis mellifera) spend much of their time inside cells, and are visible only by the tips of their abdomens when viewed through the walls of an observation hive, or on frames pulled from a typical beehive. Prior studies have suggested that honey bees spend some of their time inside cells resting or sleeping, with ventilatory movements of the abdomen serving as a telltale sign distinguishing sleep from other behaviors. Bouts of abdominal pulses broken by extended pauses (discontinuous ventilation) in an otherwise relatively immobile bee appear to indicate sleep. Can viewing the tips of abdomens consistently and predictably indicate what is happening with the rest of a bee's body when inserted deep inside a honeycomb cell? To distinguish a sleeping bee from a bee maintaining cells, eating, or heating developing brood, we used a miniature observation hive with slices of honeycomb turned in cross-section, and filmed the exposed cells with an infrared-sensitive video camera and a thermal camera. Thermal imaging helped us identify heating bees, but simply observing ventilatory movements, as well as larger motions of the posterior tip of a bee's abdomen was sufficient to noninvasively and predictably distinguish heating and sleeping inside comb cells. Neither behavior is associated with large motions of the abdomen, but heating demands continuous (vs. discontinuous) ventilatory pulsing. Among the four behaviors observed inside cells, sleeping constituted 16.9\% of observations. Accuracy of identifying sleep when restricted to viewing only the tip of an abdomen was $86.6 \%$, and heating was $73.0 \%$. Monitoring abdominal movements of honey bees offers anyone with a view of honeycomb the ability to more fully monitor when and where behaviors of interest are exhibited in a bustling nest. 


\section{Introduction}

56 Sleep is a behavior steeped in mystery, yet it appears to offer essential benefits (Rattenborg et al., 57 2007; Cirelli \& Tononi, 2008). Sleep may specifically assist with honey bee communication 58 (Klein et al., 2010, 2018) and memory (Zwaka et al., 2015), so accurately identifying sleep and knowing when and where it occurs is essential for further investigating sleep's role in honey bee ecology. To better understand sleep's benefits, or the detriments that come with sleep loss, it is essential to monitor sleep, including when it occurs in dark, hidden places. Several species of honey bees (Apis spp.) nest inside cavities, and all species of honey bees spend periods of their lives concealed inside honeycomb cells, within which much of the colony's behaviors occur and without which the colony would inevitably perish. Honeycomb is where honey bees store honey and pollen, rear brood, and where some appear to sleep. Young adult workers (callows/cell cleaners) appear to sleep almost exclusively inside cells (Klein et al., 2008, 2014), but workers spend less and less time sleeping inside cells as they age and change tasks, with foragers spending none of their time asleep inside cells (Kaiser, 1988; Klein et al., 2008). If significant periods of sleep occur within honeycomb cells, it would be wise to take inside-cell behavior into account.

Looking for sleep within the dark confines of a honey bee nest requires close examination or monitoring of bees, and modifying a nest to expose the inner workings of a colony has a long and curious history (Crane 1983), including displaying comb by adding transparent glass jars to hives (Kritsky, 2010), and designing research-friendly observation hives (von Frisch, 1967; Seeley 2 1995). Observation hives increase visibility by encapsulating frames of honeycomb between panes of glass, and this innovation has led to revolutionary discoveries in animal behavior (von Frisch 1967; Seeley, 2019). Martin Lindauer (1952) cleverly and patiently recorded the behaviors of individual honey bee workers in a modified observation hive that allowed him to observe activities within a subset of honeycomb cells. Lindauer made a point of recording when a bee was "Müssig" (idle), and concluded that time spent exhibiting this behavior, a portion of which occurred inside cells, far outweighed the time spent performing other tasks (e.g., bee \#107: $68 \mathrm{~h} 53 \mathrm{~min}$ out of the total $176 \mathrm{~h} 45 \mathrm{~min}$ observed). He referred to

84 bees seeking out undisturbed resting places, like empty or egg-containing cells, and spending

85 long, calm periods inside these cells. Lindauer used an icon of a couch or bed to symbolize this 
86 behavior, despite including cleaning movements and other somewhat superficially immobile

87 states in his calculations. We now know that a portion of this relatively immobile time in cells is

88 devoted to heating brood in adjacent cells (Kleinhenz et al., 2003), but to what extent the

89 remaining time is spent sleeping has never been rigorously established.

90

91 Few studies following Lindauer's observations have addressed immobility or potentially sleep-

92 like states in cells. These include reports of honey bees exhibiting a resting state ("Ruhezustand", 93 Sakagami, 1953), a "motionless" state (Moore et al., 1998), "rest" (Kaiser, 1988), or ventilatory

94 signs indicative of sleep (Sauer et al., 1998; Kleinhenz et al., 2003). Sleep is typically defined by

95 several behavioral criteria, most important of which is an increased threshold of responsivity to a

96 stimulus. An animal with an increased response threshold exhibits a specific posture during

97 states of relative immobility that are reversible (Flanigan et al., 1973). This suite of sleep signs is

98 internally controlled (Tobler, 1985), meaning that if deprived of the state, the organism will

99 respond with an increased expression of the behavior. Kaiser (1988) and Sauer et al. (2004)

100 confirmed that these coincident behavioral traits exist in honey bees.

101 Not all sleep signs can be observed simultaneously, so a dependable indicator of sleep would be

102 of great value. Antennal immobility is a feature that has been used as a proxy for sleep (Eban-

103 Rothschild \& Bloch, 2008; Hussaini et al., 2009; Zwaka et al., 2015) because the amount of

104 antennal immobility per unit time correlates with an increased response threshold (Kaiser, 1988).

105 Another feature that covaries with antennal immobility (Sauer et al., 2003) and could, therefore,

106 be an alternative proxy for sleep, is discontinuous ventilation. The honey bee's metasoma

107 (hereafter referred to as "abdomen") moves in anterior-posterior pumping motions (pulses) at

108 various rates and degrees of continuity. Easily observed extremes include "continuous" and

109 "discontinuous" ventilation, in which the interim between anterior-posterior abdominal motions

110 is consistently brief (continuous) or occasionally broken by extended pauses of at least $10 \mathrm{~s}$

111 (discontinuous; Kleinhenz et al., 2003). Honey bees exhibit continuous and discontinuous

112 ventilation inside cells (Kleinhenz et al., 2003) and outside cells (Kaiser, 1988), suggesting

113 higher and lower rates of respiration (Bailey 1954). A discontinuously ventilating honey bee

114 appears to almost always have a higher response threshold, a hallmark of sleep (Klein et al., in

115 prep.). Because it can be difficult or impossible to gauge antennal movement in a nest, especially

116 if a bee is inserted in a honeycomb cell, ventilatory activity holds promise as a more suitable 
117 indicator of sleep under natural or close-to-natural conditions. It is worth noting that antennal

118 immobility may even be a misleading indicator of sleep because brood-incubating (heater) bees,

119 which may appear to be asleep on the comb surface because of an absence of large body

120 movements, also exhibit slow to no antennal movement (Bujok et al. 2002).

121

122 Kleinhenz et al. (2003) modified Lindauer's (1952) hive manipulation and used ventilatory rates,

123 in part, to distinguish resting versus heating honey bees. We adopted this approach to peer at the

124 undisturbed activities of worker bees in comb cells to see if what can be seen outside a cell (tip

125 of abdomen; Figure 1a) can serve as a reliable indication of what is going on with the rest of a

126 bee's body inside the cell (Figure 1b-d). We hypothesized that ventilatory rate (continuous vs.

127 discontinuous ventilation) and the presence/absence of larger movements of the abdomen can be

128 used to predict behavior of bees inside cells. If correlations are robust between behavior of honey

129 bees inside cells with behavior that is observable outside cells, someone observing only the

130 posterior tips of honey bees when bees are inserted in honeycomb should be able to identify the

131 bees' behaviors, including sleep.

132

\section{Materials \& Methods}

134 We set up a small colony of honey bees in an observation hive with honeycomb positioned so

135 that the interiors of some cells were visible. We recorded bees' behaviors inside the visible cells

136 using an infrared-sensitive camera and a thermographic camera, first by surveying all of the

137 visible cells, then by zooming into and recording examples of behaviors for later analysis. We

138 classified behaviors into four categories based on body movement, ventilatory rate, and surface

139 temperatures. To test the viability of identifying behaviors based solely on viewing the portion of

140 a bee that is visible when honeycomb is exposed in a more conventional hive, we asked naïve

141 viewers to identify behaviors from a subset of the videos. The viewers used the same four

142 behavioral categories, but the videos were modified so only the posteriors of the bees were

143 visible. Their identifications, made under limited-visibility conditions, were compared to our

144 identifications, which benefitted from careful examination of behavior visible only inside the

145 cells, and surface temperatures visible using the thermographic camera.

146

147 Study organisms and hive

Peer] reviewing PDF | (2020:03:46711:2:0:NEW 24 Jun 2020) 
148 We collected one queen, two frames of honeycomb, and 800-1000 Carniolan worker honey bees

149 (A. mellifera carnica Pollman, 1879) from a bee yard hive, with permission from Dr. Jürgen

150 Tautz and the University of Würzburg (Würzburg, Germany; 4946'47' N, 958'31' E). We cut

151 out three sections of comb to fit within a honey bee mating cage (Begattungskästchen; see

152 Kleinhenz_et_al._.2003) and cleaned out most of the cells along the edges to increase our

153 likelihood of viewing visiting workers. The interiors of 93 empty cells and 22 cells with food

154 were visible along the edges of the hive (Figure 2). The sections of comb included brood cells,

155 pollen (at least 10 cells), uncapped honey, and empty cells. The comb slice on the left side of the

156 hive contained only uncapped honey and empty cells. The middle slice contained 50 capped

157 brood on the left side ( 9 were one-cell deep from the empty edge cells) and 27 capped brood on

158 the right side ( 2 were one-cell deep). The right slice contained 40 capped brood on the left side

159 ( 2 were one-cell deep) and 41 capped brood on the right side ( 2 were edge cells and 5 were one-

160 cell deep, with at least 6 uncapped larval cells toward the back of the comb). Twenty-one hours

161 after inserting the queen, followed by the workers, we introduced 49 uniquely paint-marked

162 callows using nontoxic, oil-based markers (Sharpie, Oak Brook, IL, USA). Marking did not

163 noticeably affect temperature readings in preliminary tests. The intent of introducing

164 individually-marked callows was to increase our likelihood of observing sleep inside cells,

165 because young adults appear to sleep more inside cells than older adults (Klein et al., 2008,

166 2014). The callows had been incubated at $36^{\circ} \mathrm{C}$ and collected within $24 \mathrm{~h}$ of emergence, marked

167 on dorsal side of mesosoma (hereafter referred to as "thorax") and abdomen, and placed in a

168 small cage on top of the new hive, separated from the hive by a screen. After $5 \mathrm{~h}$ of callows

169 being exposed to nest odor, the screen was removed and newly marked bees were accepted

170 without any sign of aggression. Ultimately, only a subset of the data recorded came from these

171 introduced, marked workers (see ventilatory and thermal methods, below).

172

173 The hive allowed for unrestricted access to the outdoors for the duration of the study (20-24

174 August 2008, with data collected from 23-24 August) via an entrance tunnel. The hive window

175 was replaced with a sheet of transparent polypropylene giftwrap (pbsfactory, Artikel 00347,

176 Rheinland-Pfalz, Germany) that remained in place for the entire study to allow for thermographic

177 recordings. The ambient temperature of the small room was maintained high enough by using a 
178 space heater that insulation was not used to cover the hive during any portion of the short study.

179 Diet was supplemented with honey and sugar water ad libitum.

180

\section{Behaviors of interest}

182 Four categories of behaviors were recorded: sleeping, maintaining cells, eating, and heating

183 (Table 1). Sleeping was identified by a bee's discontinuous ventilation and otherwise relative

184 immobility (see description, above). Maintaining cells (i.e., cleaning or building) was identified

185 by occasional large body movements, or obvious mandibular activity while continuously

186 ventilating (although ventilation could be difficult to assess during large body movement

187 episodes) in a cell devoid of food. Sakagami (1953) identified cleaners as externally quiet or

188 irregularly moving, rotating once in a while in a cell. Eating was rarely observed, but obvious

189 when it did occur; a continuously ventilating bee extended her tongue into a cell containing

190 liquid. Heating was identified when a bee with a relatively hot thorax was deep in a cell,

191 continuously ventilating and otherwise immobile. We have no data for bees packing pollen and,

192 because we had no uncapped brood in exposed cells, we have no data involving development or

193 direct tending of brood.

194

195 We conducted three sets of analyses: (1) We surveyed behaviors of bees visible inside cells

196 across multiple time points, and after zooming in with the video camera to record exemplars of

197 the different behaviors, we (2) analyzed a subset of the surveyed bees for ventilatory rates, then

198 (3) used the thermography to measure surface temperatures associated with a subset of the bees

199 that had been analyzed for ventilatory rates. By restricting thermal analyses to only those bees

200 for which we acquired ventilatory rate data, we could test whether heating bees could be

201 identified by ventilatory rates (and relative immobility) alone.

202

203 For survey data (Dataset S1 and Dataset S2), we scanned the cells with visible interiors $(\mathrm{n}=115)$

204 at 49 discrete time points, and recorded behavior for all bees inside cells. Surveys were separated

205 by at least $10 \mathrm{~min}$, and, because cell maintenance was so commonly observed (considered the

206 default behavior when not explicitly announced by B.A.K.), surveys sometimes started when a

207 behavior other than cell maintenance was detected to ensure sampling of these other behaviors.

208 Each survey involved examining every bee inserted at least partially inside comb cells for at least 
209 three to five seconds if obviously maintaining cells (i.e., cleaning or building), or eating, and for

210 longer ( $>10 \mathrm{~s}$, and sometimes for several minutes) if a worker appeared to be sleeping or heating

211 (Table 1, Figure 3, Movies S1-S4). Surveys stopped immediately after identifications of

212 behaviors, or after a few minutes of close-up filming for subsequent ventilatory analysis. B.A.K.

213 identified behaviors in real time and identified individually paint-marked bees by briefly shining

214 a tiny white light on the abdomen. Each behavioral count represented a unique bee within each

215 survey, but some bees were undoubtedly repeatedly measured across surveys.

217 We collected ventilatory rate data (Dataset S3) from a subset of the surveyed bees. Sleeping and

218 heating bees are relatively immobile (no major head, wing, leg, or body movements), except for

219 ventilatory motions of the abdomen, described above (for more details describing relative

220 immobility during sleep, see Klein et al. 2008). Discontinuous ventilation, identified by bouts of

221 abdominal pulses separated by pauses of stillness exceeding $10 \mathrm{~s}$, occasionally included a single,

222 isolated, apparently spontaneous abdominal jerk during one of these pauses. We excluded a pulse

223 (jerk) if isolated from other pulses by $\geq 5 \mathrm{~s}$ before and after. We recorded ventilatory rates using

224 JWatcher, an event recorder and analytical software package designed for study of behavior

225 (version 1.0, http://www.jwatcher.ucla.edu/). Recording events with JWatcher entails pressing

226 keys assigned to represent behaviors of interest on a keyboard, with event times automatically

227 recorded. M.K.B. manually pressed one key in time with a pulsing abdomen replayed at $0.3 \mathrm{x}$ the

228 normal speed, to increase accuracy and consistency of data transcription. Although we cannot be

229 certain that each behavioral recording represents a unique bee, three steps were taken to increase

230 the likelihood: (1) 12 of the 37 bees were individually marked, and individually-marked bees

231 were analyzed only once; (2) some of the recordings of unmarked bees captured several

232 unmarked bees concurrently, so each was unique within those recordings; and (3) surveys were

233 separated by at least $10 \mathrm{~min}$, and sometimes by several hours.

234

235 In addition to behaviors exhibited in exposed cells, we recorded mean surface temperature of a

236 bee's thorax $\left(\mathrm{T}_{\text {th }}\right)$ and mean surface temperature of her surroundings $\left(\mathrm{T}_{\text {surr }}\right)$ using FLIR's analysis

237 software package (ResearchIR Max version 4, FLIR Systems, Inc.) from a subset of the bees for

238 which we analyzed ventilatory rates, above (Dataset S4). To calculate the mean temperature of a

239 bee's thorax $\left(\mathrm{T}_{\mathrm{th}}\right)$, we drew a circle (within which a mean temperature could be automatically 
240 generated) over the region of interest (thorax) in an image taken at the beginning of a thermal

241 recording (several seconds after entering cell), the middle of the recording, and the end (several

242 seconds before exiting cell). To calculate the mean surface temperature of her surroundings

$243\left(\mathrm{~T}_{\text {surr }}\right)$ at identical time points, we dragged the same ellipse over three regions bordering the bee's

244 thorax: above and below thorax, and anterior to head. These regions of interest surrounding the

245 bee's thorax included almost exclusively cells and cell walls and, unlike a previous study by

246 Klein et al. (2014), did not include any portion of the bee herself. This updated method avoids

247 problems of the bee's body contributing to the measurement of $\mathrm{T}_{\text {surr. }}$. We report the difference of

$248 \mathrm{~T}_{\text {surr }}$ from $\mathrm{T}_{\mathrm{th}}$ to indicate the surface temperature of the bee relative to the surface temperature of

249 her surroundings $\left(\mathrm{T}_{\text {diff }}=\mathrm{T}_{\text {th }}-\mathrm{T}_{\text {surr }}\right)$ (Klein et al. 2014). There was no statistically meaningful

250 difference between using the mean body temperature from the middle time point versus the mean

251 of means across all three time points for any behavior, so we use the middle point when reporting

$252 \mathrm{~T}_{\text {th }}(\mathrm{W}=27,52,4,89 ; \mathrm{P}=0.65,0.94,1.00,0.07$ for bees sleeping, maintaining cells, eating, and

253 heating, respectively) and $\mathrm{T}_{\text {diff }}(\mathrm{W}=26,52,3,69 ; \mathrm{P}=0.58,0.91,0.70,0.61$ for bees sleeping,

254 maintaining cells, eating, and heating, respectively). Because these bees represent a subset of the

255 bees analyzed above (32 of the 37 bees for which we analyzed ventilatory rates; 11 of the 32

256 bees were individually marked), the same discussion of unique sampling applies here as well.

257

258 To test how predictable a behavior is from observing tips of abdomens alone, we first edited

259 video clips so that they were without sound and a dark gray bar concealed cell contents,

260 revealing only what extended beyond each cell (tip of abdomen and, sometimes, distal portions

261 of hindlegs). We placed a tiny digital mark to indicate the bee(s) of interest in each video (Figure

262 4, Movies S5-S8). B.A.K. trained 54 students for 20-30 min by showing and describing

263 behaviors (criteria: Table 1) in 12 video clips (4 sleeping, 5 maintaining cells, 2 heating, and 1

264 showing food in a cell; eating was described but not shown due to lack of additional examples

265 from our recordings). Videos used during training were not used during testing, but were made

266 available to students, had they wished to continue training on their own. Once trained, students

267 independently watched 30 video clips of bees with digitally obscured cell contents - a subset of

268 the 37 bee recordings used in our ventilatory rate analyses (11 sleeping, 6 maintaining cells, 2

269 eating, and 11 heating) - and recorded what they believed to be each bee's behavior.

270 


\section{Recording equipment}

272 We eliminated outdoor light and lit the room with a single desk lamp covered with a red acetate 273 filter (\#27 Medium Red, transparency =4\%, peak at $670 \mathrm{~nm}$, Supergel by Rosco, Stamford, CT, 274 USA), selected because honey bees may be less sensitive to frequencies beyond $600 \mathrm{~nm}$ (von 275 Frisch et al., 1977) or $650 \mathrm{~nm}$ (Dustmann and Geffcken, 2000). The same filter was applied to a 276 headlamp, used to facilitate observations. The warm lights were kept away from the hive, and 277 angled to minimize glare that would otherwise affect thermal measures. We filmed under the 278 low, red light, and with an infrared spotlight by using an infrared-sensitive video camera 279 (AGDVC 30, Panasonic, Japan) side-by-side with a thermal camera (FLIR SC660, FLIR

280 Systems Inc., Boston, MA, USA; accuracy $1^{\circ} \mathrm{C}$ or $1 \%$ of reading, according to FLIR manual and 281 FLIR technical support). We adjusted thermal camera settings to match the emissivity value of a 282 honey bee's thorax (0.97; Stabentheiner and Schmaranzer, 1987), although wax and other 283 surface temperatures were recorded for $\mathrm{T}_{\text {surr, }}$ and set the transmissivity to that of polypropylene 284 (0.89). The giftwrap used as the observation hive's window produced a nonlinear error when 285 recording temperature as temperature increased, so we adjusted absolute temperature 286 measurements (see Klein et al al. 2014 for details). Some data were taken using an audio recorder 287 (Olympus VN-4100PC Digital Voice Recorder) and later transcribed. Audio was synchronized 288 with video recordings by the researcher making a noise, followed by announcing the exact time 289 as was recorded on video when the noise was made. Bees were often pointed out when 290 announced, and this served to synchronize thermal imagery with video and audio.

291

\section{Statistical analysis}

293 Behavior surveys:

294 To determine how prevalent each behavior was within the hive, we compared total counts of

295 bees performing each behavior using a Kruskal-Wallis Rank Sum test. We then conducted post296 hoc pairwise tests using six two-sided, non-paired Wilcoxon Mann Whitney tests. To avoid 297 multiple testing problems, we corrected resulting P-values using the Holm method in the R 298 function p.adjust(). To account for day/night differences between behaviors, we conducted three 299 Kolmogorov-Smirnov tests using the R function ks.test(). This two-sided test's null hypothesis 300 states that two sets of data, $x$ and $y$, were drawn from the same continuous distribution.

301 Therefore, we set our $\mathrm{x}$ and $\mathrm{y}$ to be the day and night distributions of each behavior, respectively. 
302 We performed three such tests to include sleeping, heating, and cell-maintaining behaviors, each

303 time testing that each behavior count distribution remained the same from day to night. We did

304 not perform this test on eating behavior because we did not have a large enough sample. We used

305 local sunrise/sunset times to distinguish day and night

306 (https://www.gaisma.com/en/location/wurzburg.html).

307

308 Ventilatory rates:

309 To address whether different behaviors could be distinguished using the time separations

310 between their individual within-bout abdominal ventilation pulses ("pulse separations"), we

311 performed a Kruskal-Wallis Rank Sum test. To test specifically for differences in pulse

312 separations among behaviors, we filtered data to include only those abdominal pulses separated

313 by $<1$ s, and repeated the aforementioned Kruskal-Wallis Rank Sum test. We then conducted

314 pairwise Wilcoxon Mann Whitney tests comparing pulse separations across behavior groups. We

315 applied a Holm correction for multiple testing. Since individual bees were monitored for

316 different durations while performing behaviors inside cells, some bees could have

317 disproportionately influenced the separation interval of the behavioral category to which they

318 belonged. To account for any effect of individual bees on the timing between abdominal pulses,

319 we performed a linear mixed effects logistic regression analysis using the R library lme4 (in

320 package lmer test), with bee ID as random factor and behavior as fixed effect. Because our

321 residuals were initially not normally distributed, we performed a rank transformation before

322 conducting the regression analysis.

323

324 Thermal measures:

325 We measured $\mathrm{T}_{\text {th }}$ and $\mathrm{T}_{\text {surr }}$ across three timepoints (beginning, middle, and end of each bee's

326 behavior duration). If we were to use all temperatures in our analyses, then we would have $3 \mathrm{~T}_{\text {th }}$

327 and $9 \mathrm{~T}_{\text {surr }}$ per bee. If we were to use only the middle temperature measurements (which might

328 avoid behaviorally transitional complications), then we would have $1 \mathrm{~T}_{\text {th }}$ and $3 \mathrm{~T}_{\text {surr }}$ per bee. To

329 determine whether either method would affect behavior mean $\mathrm{T}_{\text {th }}$ or $\mathrm{T}_{\text {diff, }}$ we compared mean $\mathrm{T}_{\text {th }}$,

330 then mean $\mathrm{T}_{\text {diff }}$ of each behavior between the two methods using four Wilcoxon Mann Whitney

331 tests. Corrections for multiple testing were not necessary. Heating behavior was confirmed by

332 comparing a bee's thoracic temperature to that of the surrounding region. For temperature 
333 difference analyses, because the data were not normally distributed and the sample size was

334 relatively small, we applied the Wilcoxon Mann Whitney test with Holm correction. To see if the

335 temperature associated with behavior differed across behaviors, we applied a Kruskal-Wallis

336 Chi-square test using the $\mathrm{T}_{\text {th }}$ and $\mathrm{T}_{\text {surr }}$ from the middle timepoint thermal measurements. We then

337 conducted post-hoc pairwise Wilcoxon Mann Whitney tests with Holm correction on each of six

338 combinations of behavior pairs. We repeated these methods for $\mathrm{T}_{\text {diff. }}$ To determine whether $\mathrm{T}_{\text {diff }}$

339 changed over the duration of a bee's behavior in a cell, we used the R package nparLD (for

340 nonparametric longitudinal data; Noguchi et al., 2012) to conduct a non-parametric ANOVA-

341 type test. We applied the formula F1-LD-F1, which tests for group (behavior) differences,

342 change over time, and the interaction between group and time. $\mathrm{T}_{\text {diff }}$ was compared across

343 temperature measurement periods 1, 2, and 3 for all bees, grouped by behavior. Before analyzing

344 any thermal data, we corrected for the thermal signature of the thin film of giftwrap that

345 functioned in enclosing the observation colony. To do this, we used thermographic

346 measurements of the same neutral surface with and without the giftwrap film covering at a range

347 of room temperatures from $26.5-43.6^{\circ} \mathrm{C}$. Differences between the two measurements at the same

348 nominal temperatures were used to generate a set of correction values, which were then added as

349 offsets to all thermal measurements of the colony behind the giftwrap (Dataset S5).

350

351 Limited-visibility test:

352 To calculate the reliability of identifying behavior based on observing only the posterior tip of a bee's

353 abdomen, we applied a binomial test (Binomial Test Calculator,

$354 \mathrm{https}: /$ www.socscistatistics.com/tests/binomial/default2.aspx), with the null hypothesis that

355 determination of behavior is random and not related to the actual correct behaviors. We then corrected

356 for multiple testing using the Holm method.

357

358 We set alpha at 0.05 and report two-tailed P-values for all tests, and report errors as standard

359 deviations. M.K.B. performed all statistical tests using R (R Core Team, 2019), except for

360 binomial test on limited-visibility experiment.

361

362 Results

Peer] reviewing PDF | (2020:03:46711:2:0:NEW 24 Jun 2020) 
363 We conducted 49 surveys (21 nighttime, 28 daytime) of behaviors exhibited inside comb cells

364 across $34.5 \mathrm{~h}$. Absolute counts of each behavior differed across the surveys (Kruskal-Wallis rank 365 sum test $\left.\chi^{2}=123.3, \mathrm{df}=3, \mathrm{P} \leq 2.2 \times 10^{-16}\right)$. Of the 455 behavioral events monitored inside cells, 366 bees spent $16.9 \%$ sleeping $(n=63), 76.4 \%$ maintaining cells $(n=362), 0.4 \%$ eating $(n=2)$, and

$3676.4 \%$ heating $(\mathrm{n}=28)$. Bees slept for bouts of $1316 \pm 1038 \mathrm{~s}$ (range: $257-3346 \mathrm{~s}$ ), maintained

368 cells for $237 \pm 257 \mathrm{~s}$ (range: 61-845 s), ate for $447 \pm 233 \mathrm{~s}$ (range: 197-659 s), and heated for 956

$369 \pm 509$ s (range: 452-2214 s) $(n=7,9,3,10$ recordings of entire duration in cell for each behavior

370 category, respectively). Behaviors were exhibited day and night, with no evidence of day-night

371 bias for any behavior (2-sample Kolmogorov-Smirnov test, $\mathrm{D}=0.13,0.26,0.09 ; \mathrm{P}=0.99,0.40$,

3721.00 for sleeping, maintaining cells, and heating, respectively; eating sample size was too low for

373 test to be meaningful; Figure 5). None of the discontinuously ventilating bees exhibited visible

374 signs of wakeful activity (larger movements of body, antennal movement, chewing, etc.), and

375 because discontinuous ventilation covaries with other sleep signs (see above), "sleeping" is used

376 as a shorthand for discontinuous ventilation + relative immobility inside cells, below.

377

378 Ventilatory signatures as indicators of behavior.

379 Ventilatory patterns differed among behaviors exhibited inside cells, as evident when plotting 380 abdominal pulses (Figure 6), and time between pulses (Figure 7) (Kruskal-Wallis rank sum test, $381 \chi^{2}=185.2, \mathrm{df}=3, \mathrm{P}=2.2 \times 10^{-16}$ ). Discontinuous ventilation associated with sleep was

382 identified by having discrete bouts of abdominal pulses, with the bouts separated by at least $10 \mathrm{~s}$.

383 Bouts of pulses were separated by $34.5 \mathrm{~s} \pm 12.7 \mathrm{~s}$ (range: $10.1-336.6 \mathrm{~s}, \mathrm{n}=179$ bout separations

384 with a mean of 10 bout separations per bee across 12 bees). Pulses within bouts were separated

385 by $0.27 \mathrm{~s} \pm 0.06 \mathrm{~s}$, when excluding pulse separations $\geq 1 \mathrm{~s}$, which helped to exclude possible

386 spontaneous abdominal jerks that appeared distinct from bouts of pulses $(n=1166$ pulse

387 separations with a mean of 97 pulse separations per bee across 12 bees).

388 Continuous ventilation (by bees maintaining cells, eating, or heating) rarely included separation

389 of pulses by greater than $10 \mathrm{~s}$ ( $\mathrm{n}=28$ out of 490 pulse separations when maintaining cells, 14 out

390 of 394 when eating, and only 16 out of 5525 when heating; Figure 6), and instead featured

391 relatively continuous abdominal pulses, which were separated by the same amount of time as

392 sleeping bees, above $(0.33 \mathrm{~s} \pm 0.08 \mathrm{~s}$ for pulse separations $<1 \mathrm{~s}, \mathrm{n}=5701$ pulse separations with 
393 a mean of 328 pulses and a mean of 78 pulse separations per bee across 25 bees; linear mixed

394 model after rank transformation, $\mathrm{F}_{3,34}=1.19 ; \mathrm{P}=0.33$ ).

395 Abdominal pulses can be difficult to discern when bees are very active (maintaining cells or 396 eating) in cells, so ventilatory rates should be viewed in the context of whether or not a bee is

397 exhibiting larger body motions.

398

399

Thermal measures as indicators of behavior.

400 Body temperatures $\left(\mathrm{T}_{\text {th }}\right)$ differed from surrounding temperatures $\left(\mathrm{T}_{\text {surr }}\right)\left(\right.$ Kruskal-Wallis $\chi^{2}=$

$\left.40121.2, \mathrm{df}=3, \mathrm{P}=9.5 \times 10^{-5}\right)$, but only when bees were heating. $\mathrm{T}_{\text {th }}$ did not differ from $\mathrm{T}_{\text {surr }}$ when 402 bees were sleeping, maintaining cells, or eating $\left(\mathrm{T}_{\text {diff }}=0.20 \pm 0.23^{\circ} \mathrm{C}\right.$ when sleeping, $0.20, \pm$ $4030.33^{\circ} \mathrm{C}$ maintaining cells, $0.86 \pm 0.31^{\circ} \mathrm{C}$ eating; $\mathrm{n}=8,10,3$ bees, and $\mathrm{W}=37.5,58.5,7$, 404 respectively; corrected P-values using Holm method $=1.0$ in each case) (Figure 8$). \mathrm{T}_{\text {th }}$ was only 405 statistically different from $\mathrm{T}_{\text {surr }}$ in heating bees $\left(\mathrm{T}_{\text {diff }}=2.62 \pm 1.37^{\circ} \mathrm{C} ; \mathrm{n}=11\right.$ bees, $\mathrm{W}=112, \mathrm{P}=$ 406 0.0032). Heating bees' $\mathrm{T}_{\text {diff }}$ was greater than other bees' $\mathrm{T}_{\text {diff }}$ (vs. sleeping: $\mathrm{W}=88, \mathrm{P}=0.0002$; 407 vs. maintaining cells: $\mathrm{W}=110, \mathrm{P}=0.0006$; vs. eating: $\mathrm{W}=32, \mathrm{P}=0.044) . \mathrm{T}_{\text {diff }}$ did not differ 408 between sleeping and maintaining cells $(\mathrm{W}=39, \mathrm{P}=0.96)$, nor did maintaining cells and eating $409(\mathrm{~W}=2, \mathrm{P}=0.068)$, but eating bees' $\mathrm{T}_{\text {diff }}$ was greater than sleeping bees' $(\mathrm{W}=0, \mathrm{P}=0.044)$. A 410 heating bee's body temperature visibly differed from her surrounding temperature when using 411 thermal imagery (Figures 8, 9a-b; Movies S9-S10), and we used this visible difference to initially 412 identify heating bees, prior to analyzing ventilatory rates. Our aim here is to quantitatively 413 confirm this difference $\left(\mathrm{T}_{\text {diff }}\right)$ so that we can confidently associate heaters' telltale heat emission 414 with complementary behaviors (immobility + continuous ventilation) to confirm that the 415 complementary behaviors alone can be used to distinguish heating bees from bees exhibiting the 416 other behaviors. Ventilatory rates are important because a heating bee's thoracic temperature 417 fluctuates over time (Kleinhenz et al._2003; Figure 9c, Movie S11), and a relatively hot thorax 418 does not necessarily mean a worker is actively performing as a heater, but could instead be 419 transitioning into another behavioral state (Figure 9d, Movie S12).

420 Time spent exhibiting a behavior inside cells (beginning, middle, and end of stay) did not affect 421 relative body temperature $\left(\mathrm{T}_{\text {diff }}\right.$; ANOVA-Type statistic $\left.=0.48, \mathrm{df}=1.7, \mathrm{P}=.0 .58\right)$.

422

423 Reliability of observing posterior tip of abdomen for identifying behaviors. 
424 We tested how reliable watching only the posterior tip of a bee's abdomen is for identifying a 425 behavior when a bee is inside a cell. Fifty-four human subjects correctly identified when honey 426 bee workers were sleeping $86.6 \%$ of the time ( $n=461$ of 540 observations of 11 bees; binomial 427 test, expected $=0.25 ; \mathrm{z}=32.3, \mathrm{P}=4.0 \times 10^{-5} ; 13.5 \%$ misidentifications, with $8.1 \%$ identified as 428 heating), maintaining cells $50.1 \%\left(\mathrm{n}=174\right.$ of 353 observations of 7 bees; $\mathrm{z}=10.5, \mathrm{P}=4.0 \times 10^{-}$

429 5; most common misidentification: 49.2\% eating), eating 70.4\% ( $n=76$ of 108 observations of 2 430 bees; $\mathrm{z}=10.8, \mathrm{P}=4.0 \times 10^{-5}$; most common misidentification: $31.5 \%$ maintaining cells), and 431 heating $73.0 \%\left(n=446\right.$ of 617 observations of 12 bees; $z=27.1, P=4.0 \times 10^{-5}$; most common 432 misidentification: $18.5 \%$ maintaining cells). Participants typically reported difficulty determining 433 behavior due to blurriness of abdomen ( 1 video) or jostling of bee by other bees (1-2 videos). All 434 percentages are means of percentages across bees to address effect of bee, some behaviors of 435 which were more difficult than others to identify. For this reason, percentages may not sum 436 perfectly to 100 .

437

\section{Discussion}

439 Of the behaviors we recorded inside comb cells, sleep made up $16.9 \%$ of the observations, 440 second only to maintaining cells. Maintaining cells and eating were easily identified when 441 observing movement of body or mouthparts, and contents of the cell. Sleeping and heating bees

442 lacked large movements of body or head, and were distinguished from each other using 443 ventilatory rates (discontinuous vs. continuous pulses of the abdomen, respectively) and body 444 surface temperature (relative to surrounding surface temperature). When visibility was restricted 445 (i.e., when the contents of cells were obscured and only the posterior tips of honey bees' 446 abdomens were visible), maintaining cells and eating were difficult to distinguish from each 447 other, but sleeping and heating were identifiable based on ventilatory rates and lack of major 448 body motions alone ( $86.6 \%$ and $73.0 \%$ of observations were correctly identified, respectively). 449 We used these two indicators to initially identify sleeping bees and, despite the relative ease of 450 using thermography to distinguish heating bees, the same two indicators (ventilatory rate and 451 lack of major body motions) appear most reliable to identify heating as well. We base this on the 452 fact that a heating bee's temperature can fluctuate, or confusion can arise when bees transition 453 from one behavior to the next (Figure 9c-d, Movies S11-S12). We also base this on the high 
454 reliability of identifying heating bees in our limited-visibility reliability test, which we expect

455 would increase by training observers for longer than 20-30 min.

456

457

458

459

460

461

462

463

464

465

466

467

468

469

470

471

472

473

474

475

476

477

478

479

480

481

482

483

484

485

This study's findings match or differ from other studies in revealing ways. Foragers sleep more during the night than during the day (Kaiser, 1988; Sauer et al., 2003; Sauer, Herrmann \& Kaiser, 2004; Eban-Rothschild \& Bloch, 2008; Klein et al., 2008), but in this study sleep did not occur more at night (Figure 5), suggesting that we were likely observing younger workers (e.g., cell cleaners and nurse bees). These younger "hive" bees sleep primarily in cells, and behave arrhythmically (Sauer et al., 1998; Sauer et al., 1999;_Eban-Rothschild_ \& Bloch _. 2008; Klein et al._._2008__2014; but see a report of day-night differences inside cells in Moore et al., 1998). Bees were sleeping in $16.9 \%$ of observations, which falls within the wide range of caste-dependent sleep observed inside cells by Klein et al. (200요 $)$ (1.6\% observations of foragers $-39.4 \%$ of cell cleaners). Comparisons with Lindauer (1 19252 ) are not feasible because he recorded data from only two individuals under relatively normal conditions, did not distinguish discontinuously ventilating or restful states from superficially similar behavioral states, and did not specify whether calculations were based on idleness exhibited within versus outside cells. Sleeping bees' surface temperatures did not differ from their surroundings, and were slightly higher $\left(\mathrm{T}_{\text {th }}=34.7\right.$ $\pm 0.8^{\circ} \mathrm{C}, \mathrm{n}=8$ bees) than were reported in "resting" bees by Kleinhenz et al. (20을), which were also measured inside cells $\left(32.7 \pm 0.1^{\circ} \mathrm{C}-33.4 \pm 0.3^{\circ} \mathrm{C}, \mathrm{n}=5\right.$ bees $)$. These resting bees exhibited discontinuous ventilation, with inter-bout durations lasting up to $58 \mathrm{~s}$ (vs. $34.5 \mathrm{~s} \pm 12.7$ $\mathrm{s}$, lasting up to $337 \mathrm{~s}$ in this study). Heating bees are typically notably hotter than their surroundings, but the contrast was not as extreme in this study $\left(\mathrm{T}_{\text {diff }}=2.6 \pm 1.4^{\circ} \mathrm{C} ; \mathrm{n}=11\right.$ bees$)$ as it was in Kleinhenz et al. (2003) $\left(4.2 \pm 1.6^{\circ} \mathrm{C} ; \mathrm{n}=8\right.$ bees), but the body temperatures were equally high in both studies $\left(\mathrm{T}_{\text {th }}=38.7 \pm 1.6^{\circ} \mathrm{C}, \mathrm{n}=11\right.$ bees; $38.3 \pm 1.6^{\circ} \mathrm{C}, \mathrm{n}=8$ bees $)$.

\section{Limitations of study}

Our observation hive approximated natural conditions in that it was kept in a relatively dark and warm room, featured combs spaced natural distances apart, contained food and brood, the queen was free-roaming, and an entrance allowed full access outdoors. Despite these similarities to natural nests, we supplied the colony with food ad libitum, and comb was limited to narrow slices attached on one side to a plastic window. Reports by Gontarski and Geschke (as communicated by von Frisch, 1967, p. 7), suggest that 500 or 500-1000 members are sufficient

Peer) reviewing PDF | (2020:03:46711:2:0:NEW 24 Jun 2020) 
486 for developing the same division of labor as in normal colonies, but we cannot know if our tiny 487 colony (800-1000 bees) developed a natural division of labor during this short study. It is

488 important to note that the cells visible along one edge of each comb from which we collected our 489 data may present behavioral biases, which would affect results related to the proportions of 490 behaviors exhibited in cells reported in our surveys. Contents removed from edge cells to 491 increase visibility of comb cells could have caused increased cell cleaning and building activity.

492 We wanted to increase the likelihood of observing sleep in the visible cells, so our emptying of 493 edge cells could have caused a higher rate of discontinuous ventilation within these edge cells.

494 Small numbers of brood or small size of comb could have resulted in unnatural rates of heating, 495 as well. Our limited-visibility reliability test for predicting behaviors featured a lateral view of 496 abdominal tips (Figure 4) when the typical view would be posterior view of abdominal tips 497 (Figure 1a). The limited-visibility test included only three bees eating, and the sole training video 498 devoted to eating did not include eating behavior, only presence of food with description of 499 behavior.

500

\section{Why sleep inside cells?}

502 Accounting for sleep inside honeycomb may help to resolve contradictory or confusing evidence

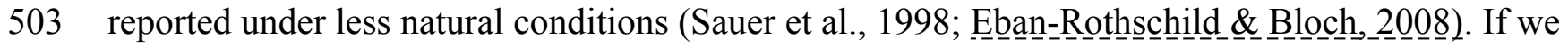
504 can rely on discontinuous ventilation + absence of major body motions as markers of sleep in 505 limited-visibility, in-cell situations, the youngest adult workers spend more time asleep than later 506 in life (Klein et al., 2008). Sleeping more earlier in life is normal across animals, and much 507 research has considered the current utility of this standard feature of sleep ontogeny. Cell 508 cleaners and nurse bees sleep primarily inside cells that are located in or close to brood comb, 509 and this could be for a variety of functionally interesting reasons (see Klein et al 510 cells may protect sleeping adults from being disturbed, which could reduce the damaging effects 511 associated with sleep fragmentation. Comb cells could provide warmth for regenerative or 512 cognitive processes, or serve as a site that reduces sleepers' interference with other workers 513 bustling about the comb. Alternatively, sleeping in cells could be a nonadaptive behavior, during 514 which honey bees simply use comb cells as a default site between acts of cell maintenance, 515 nursing, or heating. 
517 Poets, philosophers, and scientists have long pondered the societal marvels of honey bee colonies

518 (Preston, 2006), and making visible the bees' activities is a pursuit that has changed our

519 understanding of what nonhuman animals are capable of. Activities, like sleeping, can be

520 difficult to access, particularly when performed inside honeycomb hidden within a dark tree

521 hollow. What specific benefits are conferred by bees sleeping inside cells awaits further

522 investigation, and likely will depend on technical innovations involving noninvasive imaging of

523 standard hives or natural nests, or testing sleep and sleep loss in noncircadian subjects.

524

525 Conclusions

526 The best view of a honey bee inside a honeycomb cell is typically restricted to the tip of its

527 abdomen, under the best of circumstances. We hypothesized that even with such constraints, the

528 capacity to identify sleep and other behaviors can be high, based on brief observations of the

529 ventilatory rates (discernible by timing of abdominal pulsing motions) combined with the

530 presence or absence of major body movements. Viewing bees inside cells using a special hive

531 and filming with an infrared-sensitive camera and thermal camera made identifying all behaviors

532 relatively easy in this study, but identifying sleeping or heating bees was also reliable with the

533 limited visibility available to an observer without this special hive or thermal camera. Simply

534 observing ventilatory movements, as well as larger motions evident in the tip of a bee's abdomen

535 was sufficient to noninvasively identify sleeping or heating inside comb cells. Cell maintenance

536 was frequently confused with eating under limited visibility conditions, but both were clearly

537 distinguishable from sleeping and heating. Sleeping and heating were accurately identified

538 (86.6\% and $73.0 \%$ of observations, respectively) by observing ventilatory rates (discontinuous

539 versus continuous, respectively), combined with a lack of major body movements. Although

540 reliability of identifying behaviors was high, the specialized hive we used may have biased

541 proportions of time bees slept, heated, ate, or maintained cells. Sleep appeared frequently enough

542 to suggest that it is an important behavior experienced within honeycomb cells, supporting

543 previous examinations of sleep inside comb cells, and lending credibility to future ventures,

544 which can rely on similarly less invasive manipulations to reveal the dynamics and functions

545 related to sleep in nature.

546

547 Acknowledgements 
548 Jürgen Tautz, Hartmut Vierle, and the entire BEEgroup generously hosted B.A.K.'s research at

549 the University of Würzburg. Sven Mayer and Dirk Ahrens-Lagast ably and graciously assisted

550 with innovative beekeeping. Markus Mika helped to translate a portion of Lindauer's 1952

551 manuscript for us. Alistair Alesch edited video clips for testing predictability of behaviors based

552 on visibility of abdominal tips alone, and University of Wisconsin - La Crosse students took the

553 limited-visibility test. David Reineke (University of Wisconsin - La Crosse) and Jeff Oliver and

554 Keaton Wilson (University of Arizona Library) contributed statistical and R coding consultation.

555 Logan Schoolcraft provided help in data preparation. Bryant Tran assisted with video editing and

556 file processing. Laura Still and Melody Latronico assisted with some preliminary data

557 transcription. Two anonymous reviewers and Stephen Pratt provided profoundly helpful critiques

558 and suggestions. As always, we thank our sleeping, cell-maintaining, eating, and heating honey

559 bees.

560

561

562

\section{References}

563

564

565

566

567

568

569

570

571

572

573

574

575

576

Bailey L. 1954. The respiratory currents in the tracheal system of the adult honey-bee. Journal of Experimental Biology 31:589-593

Bujok B, Kleinhenz M, Fuchs S, Tautz J. 2002. Hot spots in the beehive. Naturwissenschaften 89:299-301.

Crane E. 1983. The archaeology of beekeeping. Ithaca, NY: Cornell University Press.

Cirelli C, Tononi G. 2008. Is sleep essential? PLoS Biology. 6:1605-1611.

Dustmann JH, Geffcken H. 2000. Bienen können Farben unterscheiden. Nieders. Landesinstitut für Bienenkunde (Verleger), Celle.

Eban-Rothschild AD, Bloch G. 2008. Differences in the sleep architecture of forager and young honeybees (Apis mellifera). Journal of Experimental Biology 211:2408-2416. DOI: 10.1242/jeb.016915.

Flanigan WF, Wilcox RH, Rechtschaffen A. 1973. The EEG and behavioral continuum of the crocodilian, Caimen sclerops. Electroencephalography and Clinical Neurophysiology 34:521-538. 
577 Hussaini SA, Bogusch L, Landgraf T, Menzel R. 2009. Sleep deprivation affects extinction but

578

579

580

581

582

583

584

585

586

587

588

589

590

591

592

593

594

595

596

597

598

599

600

601

602

603

604

605

606

607

not acquisition memory in honeybees. Learning \& Memory 16:698-705. DOI: 10.1101/lm.1578409.

Kaiser W. 1988. Busy bees need rest, too: Behavioural and electromyographical sleep signs in honeybees. Journal of Comparative Physiology A 163:565-584. DOI: 10.1007/BF00603841.

Klein BA, Klein A, Wray MK, Mueller UG, Seeley TD. 2010. Sleep deprivation impairs precision of waggle dance signaling in honey bees. Proceedings of the National Academy of Sciences 107:22705-22709. DOI: 10.1073/pnas.1009439108.

Klein BA, Olzsowy KM, Klein A, Saunders KM, Seeley TD. 2008. Caste-dependent sleep of worker honey bees. Journal of Experimental Biology 211:3028-3040. DOI: 10.1242/jeb.017426.

Klein BA, Stiegler M, Klein A, Tautz J. 2014. Mapping sleeping bees within their nest: spatial and temporal analysis of worker honey bee sleep. PLOS ONE 9:e102316. DOI: 10.1371/journal.pone.0102316.

Klein BA, Vogt M, Unrein K, Reineke DM. 2018. Followers of honey bee waggle dancers change their behaviour when dancers are sleep-restricted or perform imprecise dances. Animal Behaviour 146:71-77. DOI: 10.1016/j.anbehav.2018.10.010.

Kleinhenz M, Bujok B, Fuchs S, Tautz J. 2003. Hot bees in empty broodnest cells: heating from within. Journal of Experimental Biology 206:4217-4231. DOI: 10.1242/jeb.00680.

Kritsky G. 2010. The quest for the perfect hive: a history of innovation in bee culture. New York: Oxford University Press.

Lindauer M. 1952. Ein Beitrag zur Frage der Arbeitsteilung im Bienenstaat. Zeitschrift für Vergleichende Physiologie 34:299-345. DOI: 10.1007/BF00298048.

Moore D, Angel JE, Cheeseman IM, Fahrbach SE, Robinson GE. 1998. Timekeeping in the honey bee colony: integration of circadian rhythms and division of labor. Behavioral Ecology and Sociobiology 43:147-160. DOI: 10.1007/s002650050476.

Noguchi K, Gel YR, Brunner E, Konietschke F. 2012. nparLD : An R software package for the nonparametric analysis of longitudinal data in factorial experiments. Journal of Statistical Software 50:12. https://doi.org/10.18637/jss.v050.i12

Preston C. 2006. Bee. London: Reaktion Books.

Peer] reviewing PDF | (2020:03:46711:2:0:NEW 24 Jun 2020) 
608 R Core Team. 2019. R: A language and environment for statistical computing. R Foundation for

609

610

611

612

613

614

615

616

617

618

619

620

621

622

623

624

625

626

627

628

629

630

631

632

633

634

635

636

637

638

Statistical Computing, Vienna, Austria. URL http://www.R-project.org/.

Rattenborg NC, Lesku JA, Martinez-Gonzalez D, Lima SL. 2007. The non-trivial functions of sleep. Sleep Medicine Reviews. 11:405-409.

Sakagami SF. 1953. Untersuchungen über die Arbeitsteilung in einem Zwergvolk der Honigbiene. Beiträge zur Biologie des Bienenvolkes, Apis mellifera L. I. Japanese Journal of Zoology 11: 117-185.

Sauer S, Happel U, Neubecker R, Menna-Barreto L, Herrmann E, Kaiser W. 1999. Ontogeny of the circadian rest-activity cycle in honey bees kept in isolation. In: Elsner N, Eysel U. Proceedings of the 1st Göttingen Conference of the German Neuroscience Society, vol. II: 27th Göttingen Neurobiology Conference. Stuttgart: Georg Thieme Verlag. p.241.

Sauer S, Herrmann E, Kaiser W. 2004. Sleep deprivation in honey bees. Journal of Sleep Research 13:145-152. DOI: 10.1111/j.1365-2869.2004.00393.x.

Sauer S, Kinkelin M, Herrmann E, Kaiser W. 2003. The dynamics of sleep-like behaviour in honey bees. Journal of Comparative Physiology A: Sensory, Neural, and Behavioral Physiology 189:599-607. DOI: 10.1007/s00359-003-0436-9.

Sauer S, Menna-Barreto L, Kaiser W. 1998. The temporal organization of rest and activity in newly emerged honey bees kept in isolation - initial results. Apidologie 29: 445-447.

Seeley TD. 1995. The wisdom of the hive: the social physiology of honey bee colonies. Cambridge, Mass: Harvard University Press.

Seeley TD. 2019. The lives of bees: the untold story of the honey bee in the wild. Princeton, NJ: Princeton University Press.

Stabentheiner and Schmaranzer. 1987. Thermographic determination of body temperatures in honey bees and hornets: calibration and applications. Thermology 2:563-572.

Tobler I. 1985. Deprivation of sleep and rest in vertebrates and invertebrates. In: Inoue S, Borbely AA, editors. Endogenous sleep substances and sleep regulation (Taniguchi Symposia, series no. 8). Utrecht: VNU Science Press. pp.57-66.

von Frisch K. 1967. The dance language and orientation of bees. Cambridge, MA: The Belknap Press.

von Frisch K, Lindauer M, Inst Wiss Film. 1977. Nachweis des Farbensehens bei der Honigbiene. Film C 1263 des IWF, Go“ttingen. Publication of Lindauer M,

Peer) reviewing PDF | (2020:03:46711:2:0:NEW 24 Jun 2020) 
639 Publ Wiss Film, Sekt Biol, Ser. 14: Nr. 23/C 1263 (1981), 8 S.

640 Zwaka H, Bartels R, Gora J, Franck V, Culo A, Götsch M, Menzel R. 2015. Context odor

641 presentation during sleep enhances memory in honeybees. Current Biology 25:2869-

642 2874. DOI: $10.1016 /$ j.cub.2015.09.069.

643 


\section{Figure 1}

Figure 1. Visibility of honey bee workers deep inside cells in observation hives.

(a) Clear view of posterior end of worker abdomen, center. This is the typical view of an adult bee inside a cell when removing frames from a beehive, or, in this case, when viewed through the glass window of an observation hive (Würzburg, Germany, 2006). (b-d) Unusually clear views of bees sleeping inside cells built on windows of an observation hive (USA, 2019). Sometimes bees construct comb against the glass of an observation hive, exposing the occasional bee's activities within comb cells. Photos by Barrett Klein. 


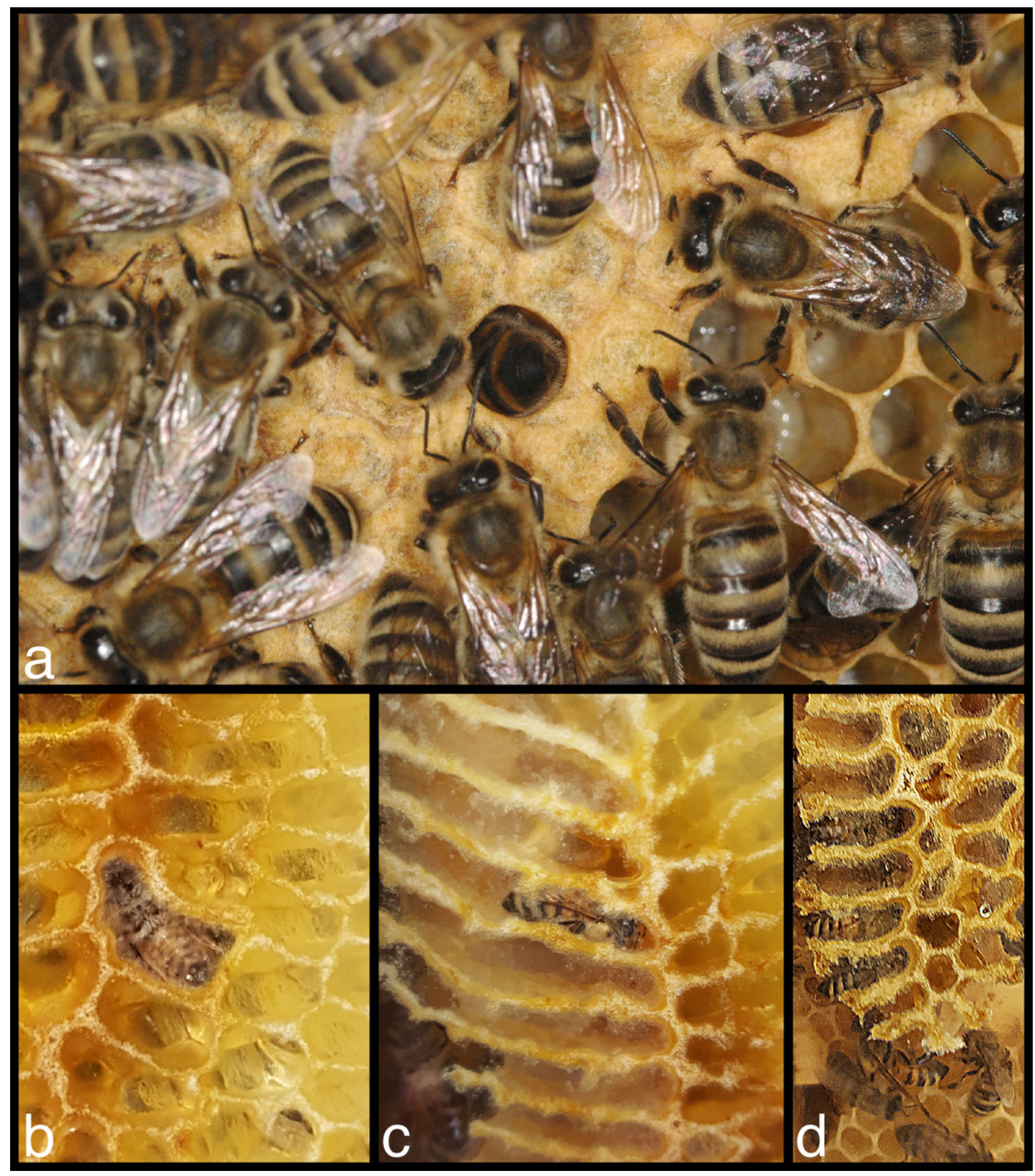




\section{Figure 2}

Figure 2. Observation hive with slices of honeycomb and exposed cells.

(a) Still image from infrared video of inhabited hive, with hive entrance leading to tubular tunnel at lower left. (b) Slices of comb were held in place by nails inserted through wood frame and comb slices were aligned at natural distances from each other. (c) Comb on right is angled prior to study to show width and some of cell contents, including uncapped and capped brood. Bottom, back corner of each comb was removed to allow easy travel by workers through the hive. Photos by Barrett Klein. 


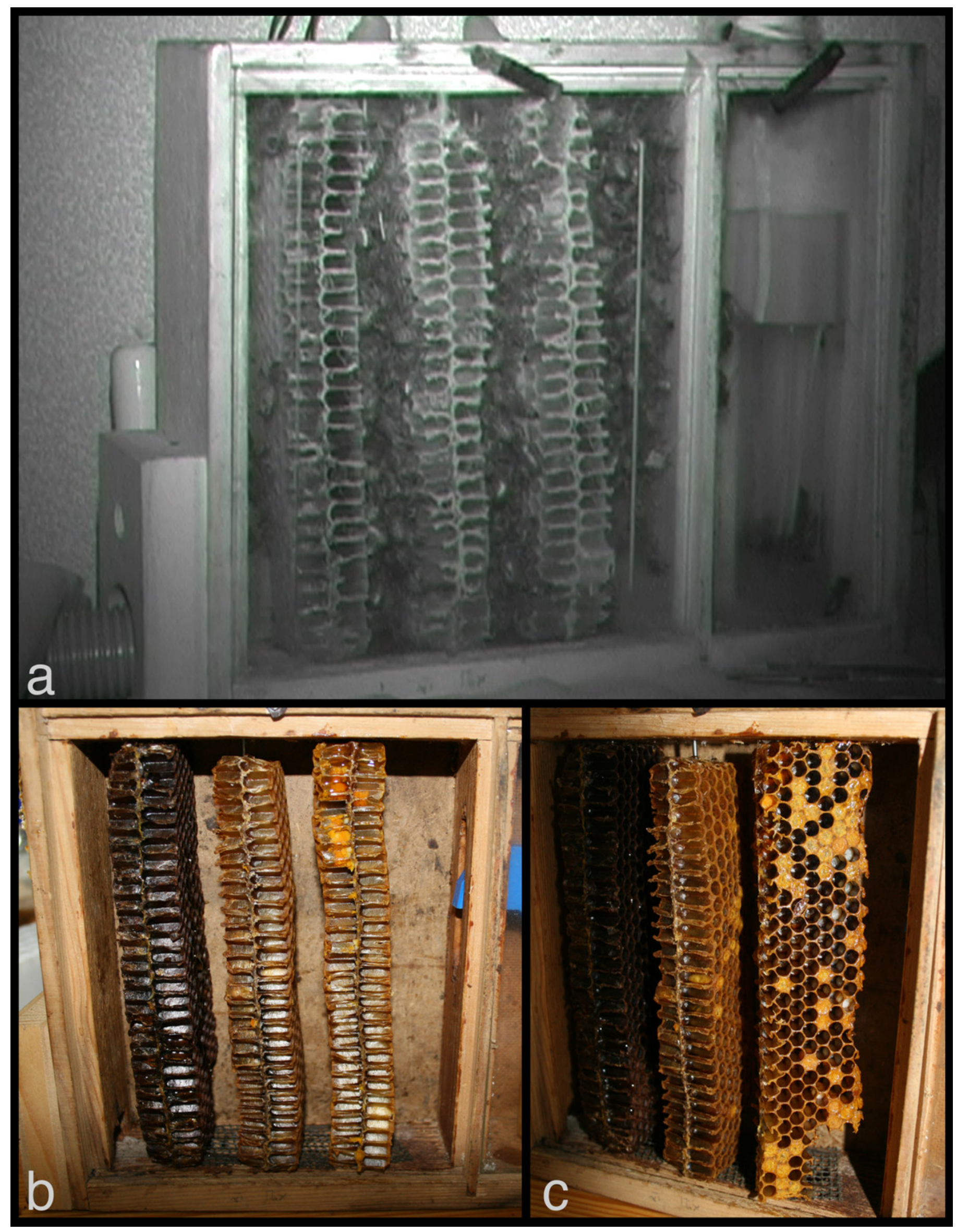




\section{Figure 3}

Figure 3. Still images from infrared-sensitive videos of behaviors, with all honey bees head-first inside cells.

(a) Sleeping bee, center cell, is facing left, venter up. (b) Bee is eating, with mouthparts extended and body less fully inserted in cell; facing left, venter down. (c) Heating bee is facing left, venter facing observer (sideways). (d) Sleeping bee, center, is facing left, venter down, and is to be compared with heating bee, at right, facing right, dorsum facing observer (sideways). All other bees inside cells are maintaining (cleaning or building) cells, including two visible in (a) and three in (b), indicated by black circles superimposed on the middle of their thoraces. Contrast and brightness alterations of image serve to highlight sleeping, eating, and heating bees. See supplementary Movies 1-4, from which these images were taken. Images by Barrett Klein. 


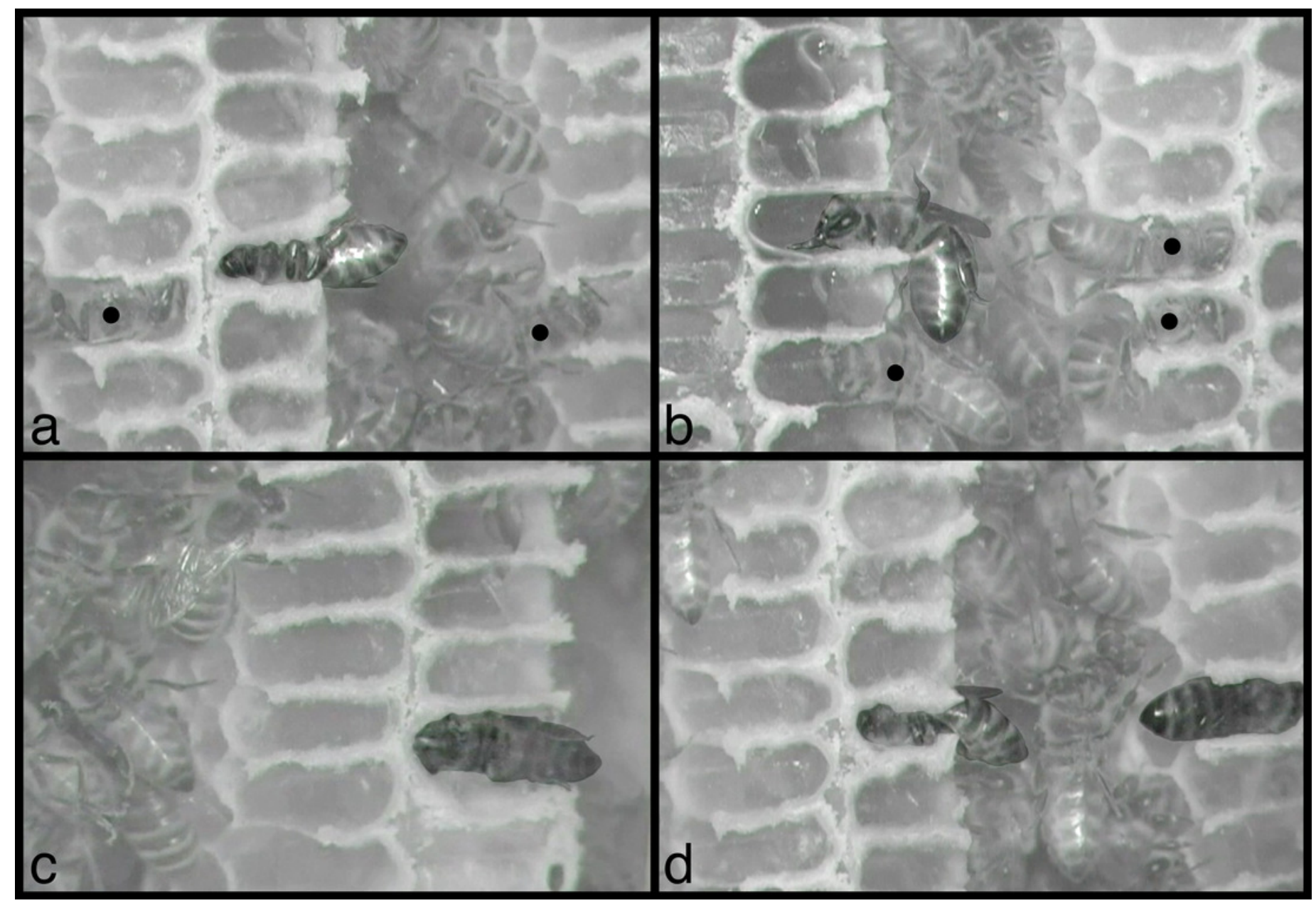




\section{Figure 4}

Figure 4. Still image from infrared test video.

Gray boxes obscure cell interiors, and small light gray rectangle within box on right marks bee of interest. Test yourself with Movies 5-8, a sample of video clips we used to test the reliability of identifying inside-cell behavior from what is visible outside the cell. (Answers included.) Photo by Barrett Klein.

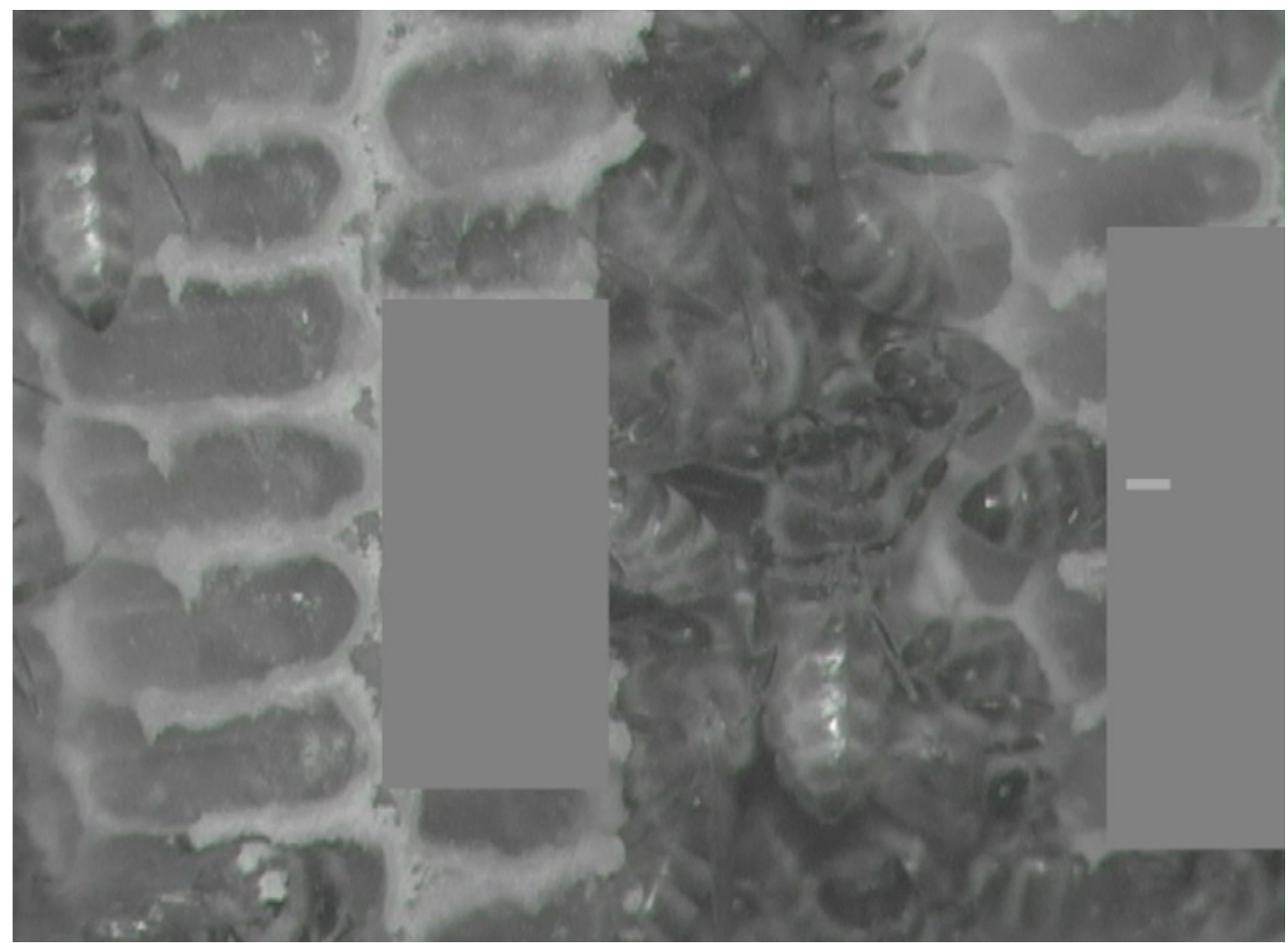




\section{Figure 5}

Figure 5. Number of observations spent sleeping, maintaining cells, eating, or heating inside cells across time.

Note that number of observations during any given survey ranged from 1-17 bees. Sleeping data are presented top-down so comparisons of number of occurrences can more easily be compared within this behavior across time. Two eating occurrences are presented here, but a third eating event was recorded for ventilatory and thermal data between surveys (Figures 6 $\& 8)$.

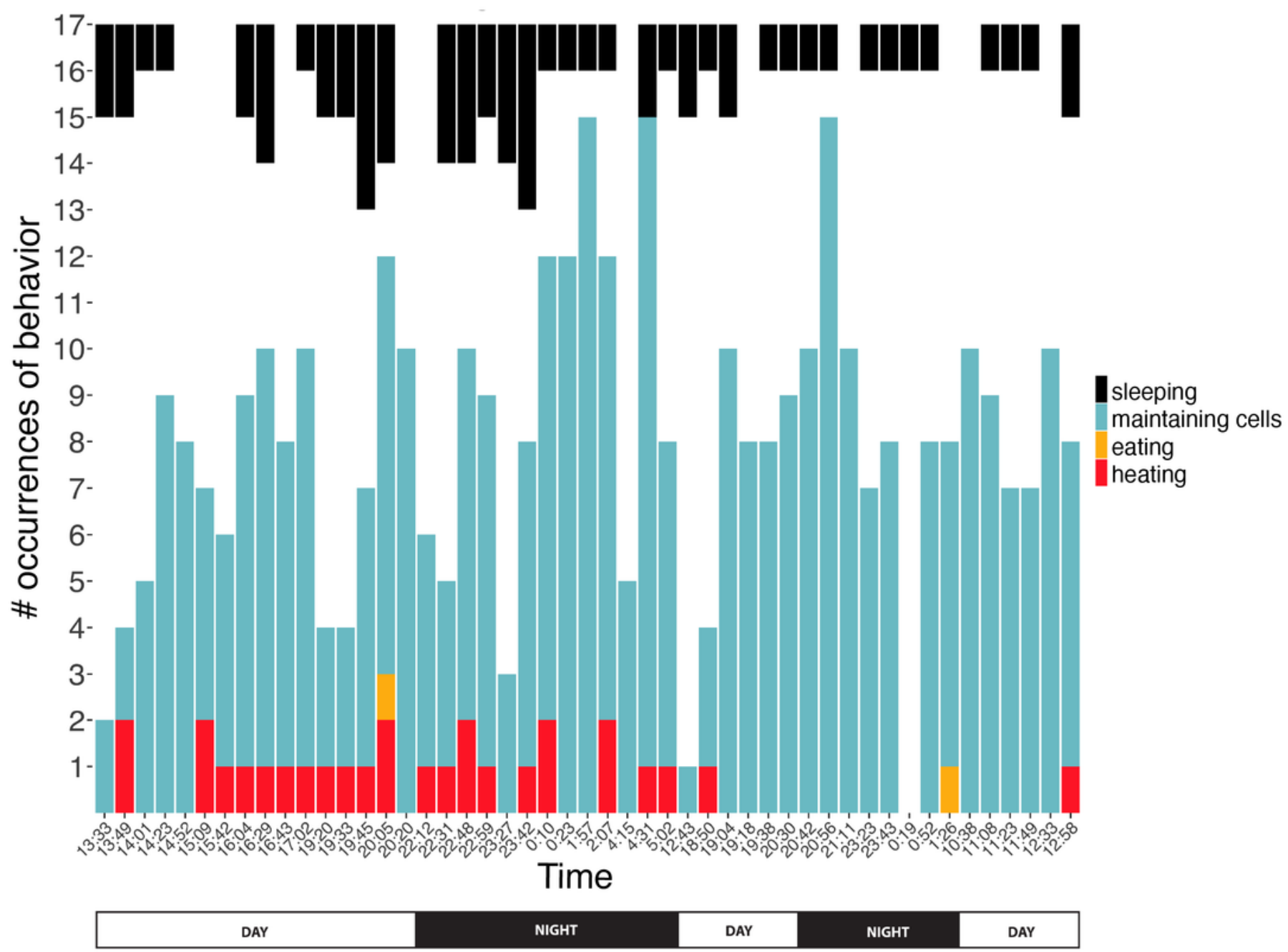




\section{Figure 6}

Figure 6. Ventilatory pulses of abdomen over time by worker bees that were sleeping, maintaining cells, eating, or heating.

Gray areas to the right of each pulse sequence signify post-recording periods (no data). Bees (y-axis) included 12 uniquely marked individuals (total $n=37$ bees; 12 sleeping, 10 cleaning, 3 eating, 12 heating).

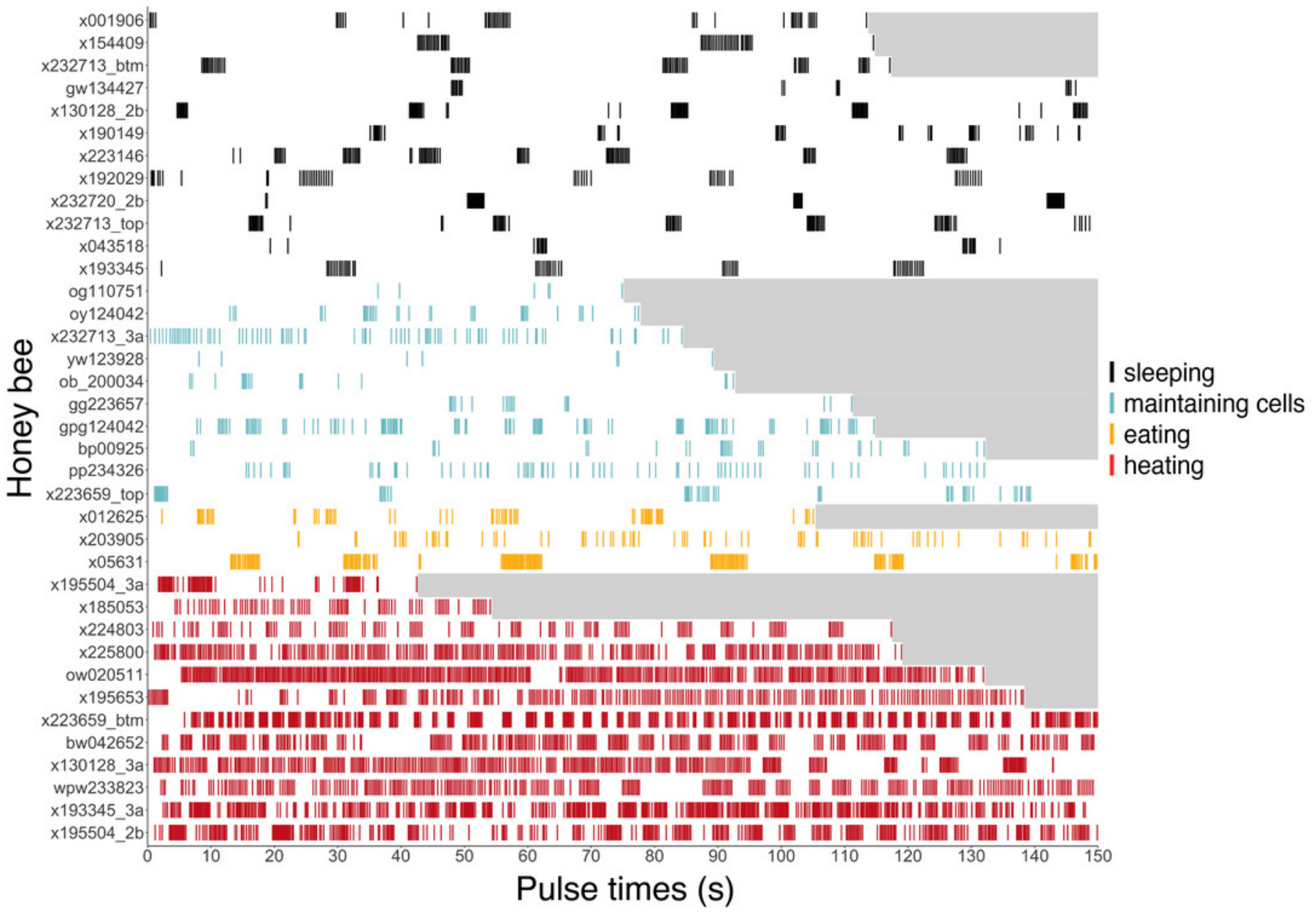




\section{Figure 7}

Figure 7. Time between pulses of the abdomen (= pulse separations) when exhibiting different behaviors.

Ventilatory behavior is commonly distinguished as either continuous or discontinuous, depending on pattern of pulse separations. (a-d) Histograms displaying frequency of pulse separations when bees were sleeping, maintaining cells, eating, or heating. Y-axes break at frequency $=14$ to show spread of data along $x$-axes; maximum $y$-values $(1166,335,328$, 5039) are superimposed above 14 in each plot. Pulse separations that were (e) long (> $10 \mathrm{~s}$ ) and typically associated with discontinuous ventilation, or ( $\mathrm{f}$ ) short $(<10 \mathrm{~s})$, by behavior. Pulses separated by $<1 \mathrm{~s}$ are typical within pulse bouts that are separated by long pauses during discontinuous ventilation (associated with sleep), and are common throughout continuous ventilation. Note different $y$-axis scales in e $\&$ f. $\left(n_{\text {pulse separations }}=1342\right.$ during sleeping, 490 maintaining cells, 394 eating, and 5525 heating; $n_{\text {bees analyzed }}=12$ sleeping, 10 maintaining cells, 3 eating, 12 heating) 


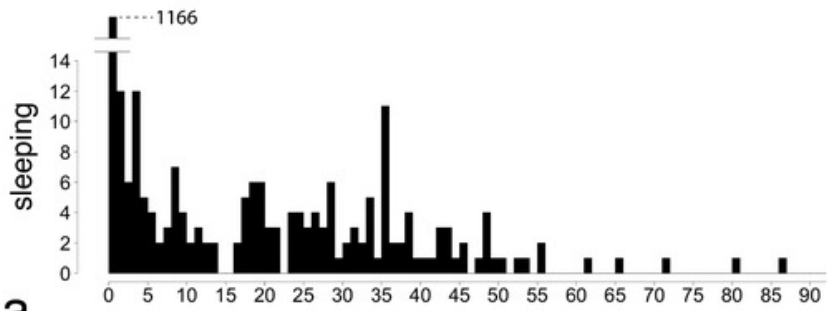

a

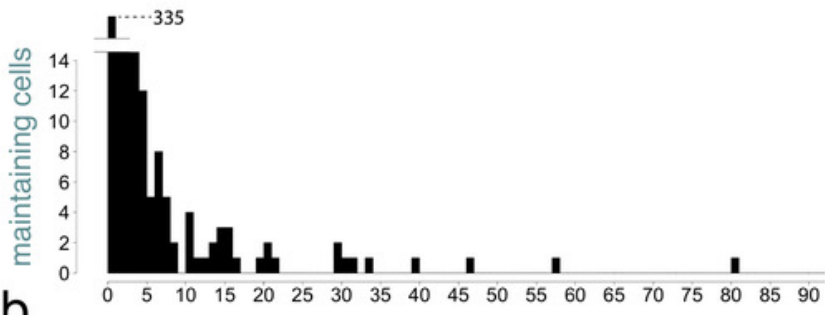

b

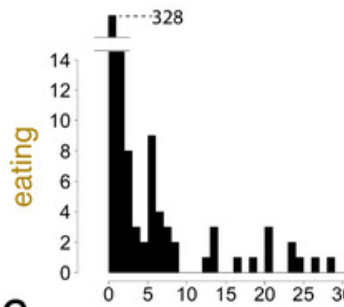

C

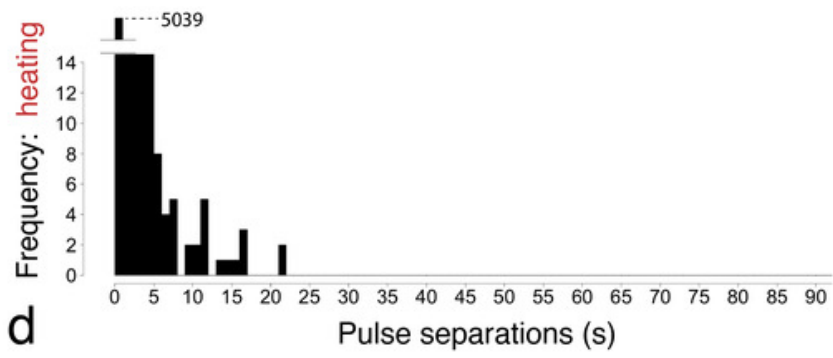

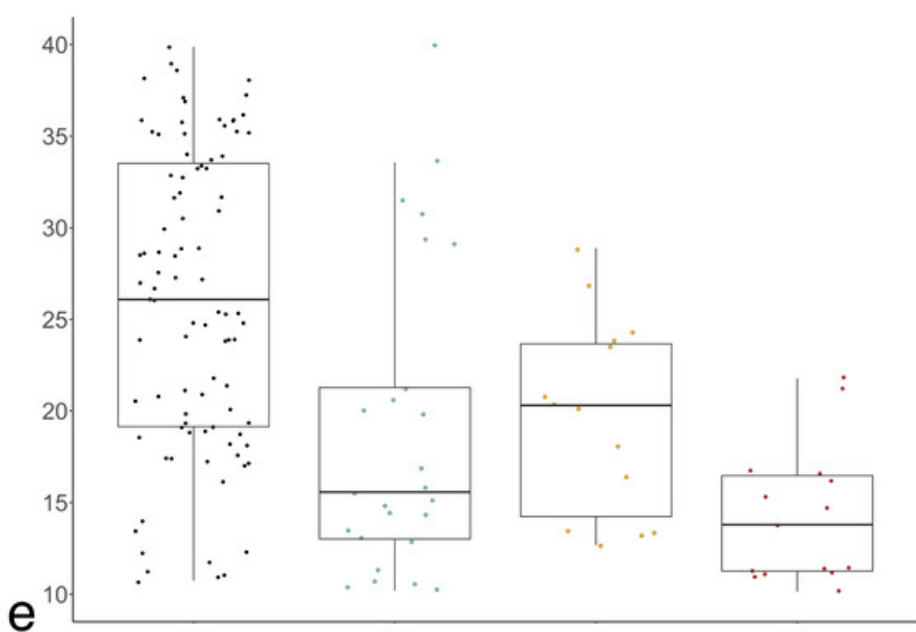

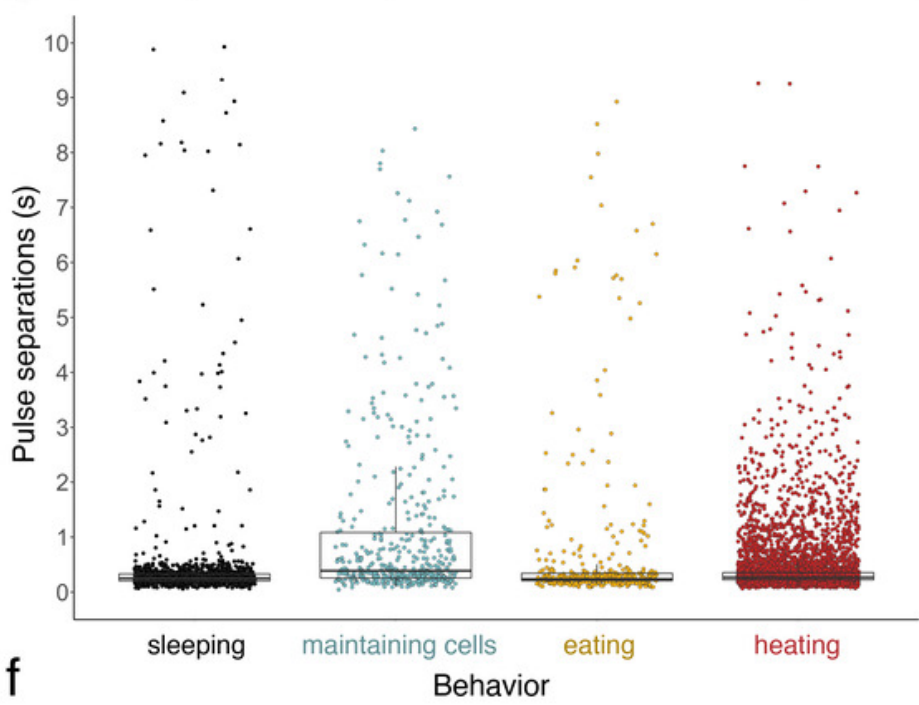




\section{Figure 8}

Figure 8. Temperatures of bees and of bees relative to their surroundings when exhibiting different behaviors.

Individual bees' thorax temperatures relative to surrounding temperatures $\left(T_{\text {diff }}=T_{\text {th }}-T_{\text {surr }}\right.$, left axis; colored circles), and absolute temperature of thorax (right axis; + signs) when sleeping, maintaining cells, eating, or heating. Solid lines represent mean temperature of $T_{\text {diff }}$ across bees for each behavior, and dashed lines represent mean temperature of thorax $\left(T_{t h}\right)$ across bees for each behavior. Temperatures are all surface measurements taken remotely with a thermal camera. Bees ( $\mathrm{x}$-axis) included 11 uniquely marked individuals (total $\mathrm{n}=32$ bees; 8 sleeping, 10 cleaning, 3 eating, 11 heating). 


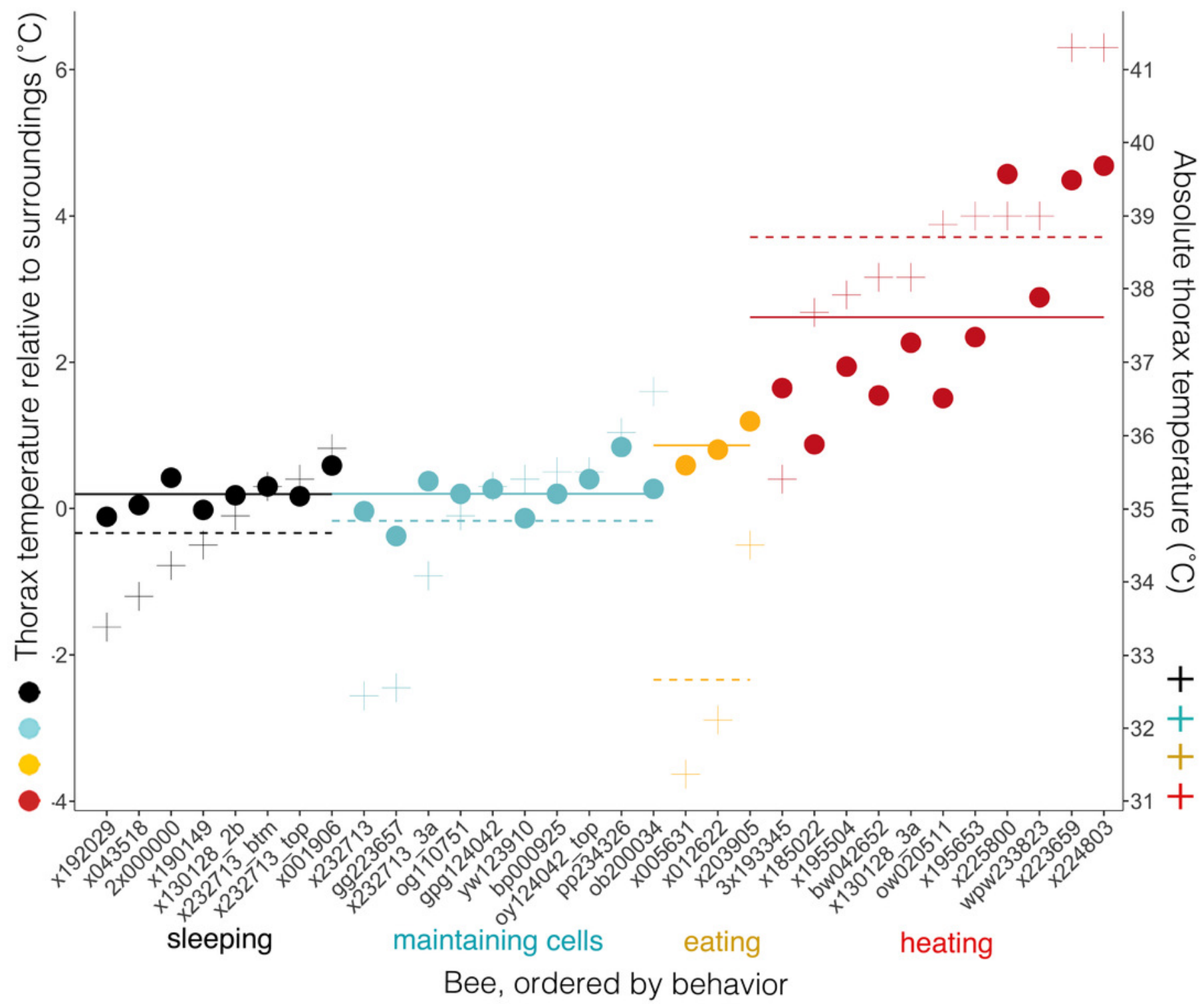




\section{Figure 9}

Figure 9. Still images from thermal imaging videos.

(a) A worker heating while inside a cell, head facing left and part of abdomen, wings, and hind leg extending outside cell, to the right. Image taken from Movie 9. (b) The two brightest spots, at left, each show the relatively hot thorax of a heating bee inside a cell, one immediately behind the plastic window of the hive (top arrow), and one that is one cell deep, seen through the wax wall of a cell (bottom arrow). These workers spent a total of ca. 5 min and 25 min heating inside these cells, respectively. Image taken from Movie 10 at $35 \mathrm{~s}$ after 21:41 h. (c) The arrows point to a heating bee with fluctuating body temperature. Images taken from Movie 11 at $10 \mathrm{~s}$ after 07:58 $\mathrm{h}$ and $2 \mathrm{~min} 48 \mathrm{~s}$ later. Total heating time exceeded 11 min. (d) Each bright spot is a relatively hot thorax, but of a bee maintaining cells, not heating. Image taken from Movie 12. 


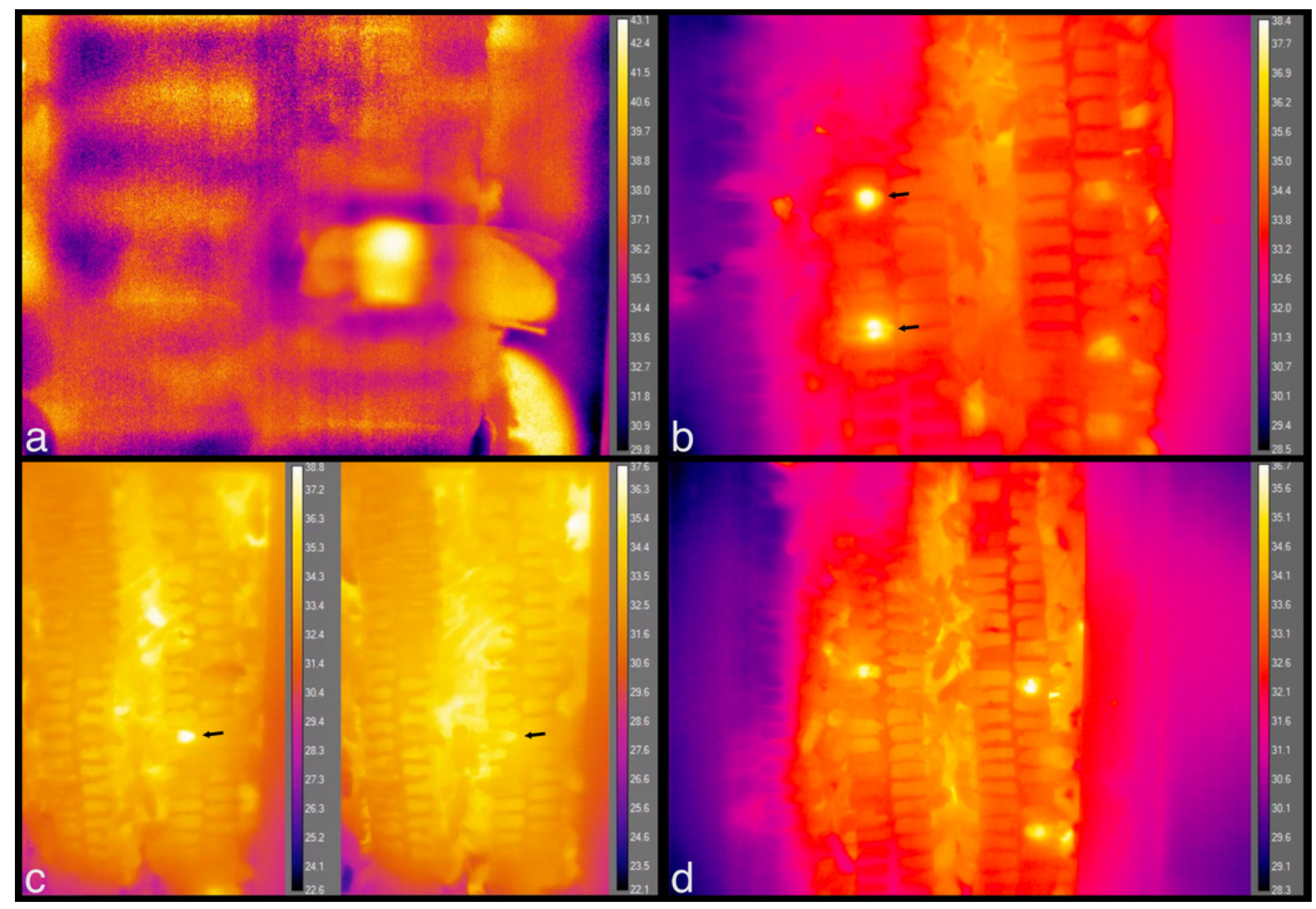




\section{Table $\mathbf{1}$ (on next page)}

Table 1. Criteria used to define behaviors of honey bees when visible in comb cells, or when visibility was limited to posterior ends of abdomens.

Honey bees were observed inside exposed comb cells (i.e., in cells on edge of comb, visible through plastic window), or visibility was limited by digitally obscuring cell interiors (for testing predictability of behavior from observations of abdominal tip alone; Figure 4). Ventilatory movements appear as anterior-posterior abdominal pulses, occasionally consolidated into "bouts." Continuous ventilation = respiratory pulses separated by $<10 \mathrm{~s}$ of immobility (rarely, if ever, > 10s); discontinuous ventilation = respiratory pulses in bouts, separated by $>10$ s of immobility (Kleinhenz et al. 2003). Sample size refers to bees for which we collected respiratory rate data. 
2 Table 1. Criteria used to define behaviors of honey bees when visible in comb cells, or when 3 visibility was limited to posterior ends of abdomens. Honey bees were observed inside exposed 4 comb cells (i.e., in cells on edge of comb, visible through plastic window), or visibility was limited by 5 digitally obscuring cell interiors (for testing predictability of behavior from observations of abdominal tip 6 alone; Figure 4). Ventilatory movements appear as anterior-posterior abdominal pulses, occasionally 7 consolidated into "bouts." Continuous ventilation = respiratory pulses separated by $<10 \mathrm{~s}$ of immobility 8 (rarely, if ever, > 10s); discontinuous ventilation = respiratory pulses in bouts, separated by $>10 \mathrm{~s}$ of 9 immobility (Kleinhenz et al. 2003). Sample size refers to bees for which we collected respiratory rate data. 10

\begin{tabular}{|c|c|c|c|}
\hline Behavior & $\begin{array}{l}\text { Criteria used to identify behavior } \\
\text { when cell interior was visible }\end{array}$ & $\begin{array}{l}\text { Criteria used to identify behavior } \\
\text { when cell interior was digitally } \\
\text { obscured (test videos) }\end{array}$ & $n$ (bees) \\
\hline Sleeping & $\begin{array}{l}\text { Discontinuously ventilating, } \\
\text { otherwise relatively immobile (Klein } \\
\text { et al. 2008) }\end{array}$ & $\begin{array}{l}\text { Discontinuously ventilating, otherwise } \\
\text { immobile }\end{array}$ & 12 \\
\hline Maintaining cells & $\begin{array}{l}\text { Body active in empty cell, often } \\
\text { obscuring continuous ventilation; } \\
\text { mandibular or antennal movement } \\
\text { commonly observed (i.e., cleaning or } \\
\text { building cells) }\end{array}$ & $\begin{array}{l}\text { Continuously ventilating, often coupled } \\
\text { with larger body movements (in and } \\
\text { out, or rotating in cell; Sakagami 1953) }\end{array}$ & 10 \\
\hline Eating & $\begin{array}{l}\text { Tongue extended in cell containing } \\
\text { liquid; continuously ventilating }\end{array}$ & $\begin{array}{l}\text { Continuously ventilating with possible } \\
\text { body movement, and only partially in } \\
\text { cell (cell contents prevent bee from } \\
\text { going deeper) }\end{array}$ & 3 \\
\hline Heating & $\begin{array}{l}\text { Continuously ventilating, otherwise } \\
\text { immobile while deep in cell; thorax } \\
\text { obviously hotter than surroundings } \\
\text { (when viewed using thermal camera) }\end{array}$ & $\begin{array}{l}\text { Continuously ventilating, otherwise } \\
\text { immobile }\end{array}$ & 12 \\
\hline
\end{tabular}

11

12 